\title{
A Novel Role of Adiponectin: Stimulator of Human SW480 Colon Carcinoma Cell Migration by Inducing an Autocrine IL-8 and MCP-1 Loop
} Janina Ratke, Bernd Niggemann, Kerstin Lang and Kurt S. Zänker*

Institute of Immunology, Witten/Herdecke University, 58448 Witten, Germany

\begin{abstract}
Colon cancer is the third most common cause of cancer, and epidemiological studies have shown that obesity increases the risk of colon cancer by $1.5-2$ folds with obesity-associated colon cancer accounting for 14$35 \%$ of total incidence. So far, solely leptin was found to promote the motility and invasion of carcinoma cells. Adiponectin is another prominent protein hormone secreted by differentiated adipocytes. However, the effect of adiponectin on migration of carcinoma cells is mostly unknown. In this study, we found that adiponectin significantly increased the locomotion of human SW480 colon carcinoma cells. This pro-migratory effect is mediated by an activation of an autocrine loop of interleukin-8 (IL-8) and monocyte chemoattractant protein-1 (MCP-1), as was shown by neutralizing antibodies. Treatment of the cells with these specific antibodies completely abrogated the adiponectin-promoted locomotion. The intracellular signal transduction underlying this effect involves the activity of the transcription factors Stat-3 and nuclear factor-kappa B (NFKB), but also the activation of the phosphatidylinositol-3-kinase/Akt pathway, as proven by the use of specific inhibitors. Blockade of NFKB activation abolished the pro-migratory effect of adiponectin by inhibiting the secretion of IL-8 and MCP-1. Here, we report on a new biological function of adiponectin in the regulation of colon cancer progression by stimulating tumor cell migration via an autocrine IL-8 and MCP-1 loop. Thus our findings have potential clinical implications, because understanding the impact of adiponectin on tumor cell migration and the underlying signal transduction mechanisms is mandatory for future development of novel therapeutics to treat obesity-associated colorectal cancer.
\end{abstract}

Keywords: Colon carcinoma; Cell migration; Adiponectin; Signal transduction

\section{Introduction}

Adipose tissue is no longer considered as inert energy depot storage but an active endocrine organ. Adiponectin is one of the most abundant gene products secreted exclusively by fat cells, with plasma concentrations in healthy humans around 3-30 $\mu \mathrm{g} / \mathrm{ml}$ [1]. Adiponectin has a broad spectrum of biological activities, e.g. it increases the body's sensitivity to insulin including stimulation of glucose uptake in skeletal muscle and suppression of glucose production in liver, and affects the lipid metabolism by decreasing tissue fatty acid content and serum lipids. Thereby, adiponectin acts through its two receptors, AdipoR1 and AdipoR2. AdipoR1 is expressed widely in various tissues, including breast tissue, with the highest level of expression in skeletal muscle, while AdipoR2 is most abundantly expressed in the liver [1]. In contrast to most adipose-tissue derived proteins, plasma adiponectin levels are found to be lower in obese than in lean subjects, and adiponectin concentrations increase with weight loss [2]. Thus, serum levels of adiponectin are markedly decreased in individuals with visceral obesity and states of insulin resistance, such as type 2 diabetes mellitus and atherosclerosis. Moreover, evidence from several studies indicates that serum levels of adiponectin in vivo are inversely associated with the risk for multiple cancers, including colon in men [3], prostate [4] as well as breast and endometrium [5,6]. This relationship is also reflected in the expression profile of adiponectin receptors, which were primarily found to be expressed solely in the malignant and not in the normal control tissue, e.g. in lung cancer there was a differential expression by disease stage [7]. Thus adiponectin may act on tumor cells directly by binding and activating adiponectin receptors and downstream signaling pathways.

The majority of mortality associated with cancer is due to metastasis of the original tumor cells to sites distant from the initial or primary tumor. A pre-requisite for metastasis is the ability of tumor cells to migrate throughout the body. This process is not an intrinsic property of the cell, but can be initiated or regulated by extracellular signaling molecules found in the environment of the tumor [3]. Accordingly we have shown before that various soluble molecules derived from divergent organ systems, e.g. neurotransmitters and adipocytokines, can induce the migration of tumor cells [8-10]. Leptin, the best studied adipocytokine so far, is a strong stimulator for the migration of colon carcinoma cells, and acts via multiple signalling pathways $[8,10]$. In vivo high leptin concentrations are accompanied by low concentrations of adiponectin. Accordingly, we hypothesized an inhibitory effect of adiponectin on the locomotory activity of SW480 cells. Therefore, in the current study we investigated the effect of adiponectin on the migration of human SW480 colon carcinoma cells and the signal transduction pathways underlying the adiponectin-driven influence on migration. Unexpectedly, we found a significant pro-migratory effect of adiponectin on human colon carcinoma cells which is mediated by a completely new autocrine interleukin- 8 and MCP-1 loop, and the intracellular signal transduction leading to the activation of the appropriate genes.

*Corresponding author: Kurt S. Zänker, MD, DVM, PhD, Institute of Immunology and Experimental Oncology, Faculty of Health Science, Department of Human Medicine, ZBAF, Witten/Herdecke University, Stockumer Str. 10, 58448 Witten, Germany, Tel: +49-2302-926-159; Fax: +49-2302-926-158; E-mail: Kurt.Zaenker@uni-wh.de

Received May 22, 2012; Accepted March 29, 2013; Published April 01, 2013

Citation: Ratke J, Niggemann B, Lang K, Zänker KS (2013) A Novel Role of Adiponectin: Stimulator of Human SW480 Colon Carcinoma Cell Migration by Inducing an Autocrine IL-8 and MCP-1 Loop. J Cancer Sci Ther 5: 150-157. doi:10.4172/1948-5956.1000202

Copyright: ( 2013 Ratke J, et al. This is an open-access article distributed under the terms of the Creative Commons Attribution License, which permits unrestricted use, distribution, and reproduction in any medium, provided the original author and source are credited. 


\section{Materials and Methods}

\section{Cell culture}

The human colon carcinoma cell line SW480 (American Type Culture Collection, Rockville, MA, USA) was cultured in Leibovitz's L-15 culture medium (PAA, Linz, Austria) supplemented with 10\% fetal calf serum (FCS; PAA), penicillin $(50 \mathrm{U} / \mathrm{ml})$ and streptomycin $(50$ $\mu \mathrm{g} / \mathrm{ml}$; Gibco) at $37^{\circ} \mathrm{C}$ humidified atmosphere.

\section{Cell migration}

We performed our conventional three-dimensional, collagenbased migration assay as described in detail previously [11]. In brief, a suspension of $9 \times 104$ tumor cells in $50 \mu$ culture medium with or without substances was mixed with $100 \mu \mathrm{l}$ of a buffered collagen solution 4 ( $\mathrm{pH} 7.4$ ), containing $1.67 \mathrm{mg} / \mathrm{ml}$ bovine collagen type I (Invitrogen, Cohesion Technologies, Palo Alto, CA). The suspension was filled into self constructed migration chambers, consisting of a microscopic glass slide, wax walls, and a cover slip on top. After polymerization of the collagen at $37^{\circ} \mathrm{C}$ in a humidified $5 \% \mathrm{CO}_{2}$ atmosphere, the migration of the cells was recorded by time-lapse video microscopy for 12 hours at $37^{\circ} \mathrm{C}$. The paths of 30 randomly selected cells were digitized by computer-assisted cell tracking and the part of migratory active cells was calculated for every 15 minutes interval. Mean locomotory activity and standard deviation were calculated for each single experiment at the steady state level.

Migratory activity was induced by $10 \mu \mathrm{g} / \mathrm{ml}$ recombinant human adiponectin (Biomol, Hamburg, Germany); we have used this concentration in the following experiments, because this concentration is close to the one found in vivo in obese patients [1]. Furthermore, we used human interleukin-8 (IL-8; 100 ng/ml; Biotrend, Cologne, Germany) and monocyte chemoattractant protein 1 (MCP-1; $20 \mathrm{ng} / \mathrm{ml}$, PeproTech, Hamburg, Germany), the PI3K inhibitor LY294002 (5 $\mu \mathrm{M}$, New England Biolabs, Frankfurt, Germany), a Stat-3 inhibitor peptide (200 $\mu \mathrm{g} / \mathrm{ml}$, Merck, Darmstadt, Germany) and the NFkB activation inhibitor (10 nM, Merck). For IL-8 as well as MCP-1 neutralizing experiments, the cells were incubated with $10 \mu \mathrm{g} / \mathrm{ml}$ of a neutralizing polyclonal anti-human IL-8 antibody (Biomol) or anti-human MCP-1 antibody (BioLegend, San Diego, CA, USA). None of the substances affected the viability of the cells at the concentrations used, as was analyzed by propidium iodide staining and flow cytometry.

\section{Immunoblotting}

The expression of the AdipoR1 and AdipoR2 receptor, IкBa (inhibitor of $\mathrm{NF \kappa B}$ ), NFkB, Akt and ERK 1/2 (extracellular signalregulated kinase $1 / 2$ ), and the phosphorylation of the latter (p-Akt, $\mathrm{p}-\mathrm{I} \kappa \mathrm{B} a, \mathrm{p}-\mathrm{NF \kappa B}$ and p-ERK1/2), was analyzed by immunoblotting. For the detection of AdipoR1 and AdipoR2, SW480 cells were incubated in culture medium without FCS, 5 whereas for I $\kappa \mathrm{B} a$, Akt and ERK1/2 expression and phosphorylation studies SW480 cells were incubated for $15 \mathrm{~min}$ or $30 \mathrm{~min}$ under the same conditions with or without the addition of $5 \mu \mathrm{M}$ LY294002. Finally, every probe was lysed in Laemmli sample buffer $\left(10 \mathrm{~min}, 95^{\circ} \mathrm{C}\right)$ [12], and lysates of $5 \times 105$ cells of each sample were applied to gel-electrophoresis. The proteins were separated and transferred to an Immobilion-P membrane (Millipore, Bedford, MA) as described previously 9 , subsequent immunoblotting was performed according to the method described therein. AdipoR1 and AdipoR2 were verified with primary goat-polyclonal antibodies (Abcam, Cambridge, UK), and after washing, the samples were incubated with a horseradish peroxidase (HRP)-conjugated secondary rabbit anti-goat (Southern Biotech, Birmingham, AL). IкBa, p-IкBa, NFkB, p-NFkB, Akt, p-Akt, ERK1/2 and p-ERK1/2 were stained with rabbit monoclonal IgG antibodies (New England Biolabs). Primary antibodies were detected using a HRP-conjugated anti-rabbit antibody (New England Biolabs). The luminescence signal was induced with chemiluminescence blotting substrate (Roche, Mannheim, Germany) and detected using a Hamamatsu C4742-98 system (Hamamatsu, Herrsching, Germany). For quantification of receptor expression and the expression of $\mathrm{I} \kappa \mathrm{B} \alpha$, the applied amounts of protein were standardized by reprobing the membrane with a beta-actin rabbit antibody (New England Biolabs). After detection of phospho-proteins membranes were stripped, too, and reprobed with the corresponding non-phospho-antibody. Staining signals of AdipoR1/R2, p-Akt, $\mathrm{p}-\mathrm{I} \kappa \mathrm{B} a, \mathrm{p}-\mathrm{NF} \kappa \mathrm{B}$ and $\mathrm{p}-\mathrm{ERK} 1 / 2$ were quantified using the Image) software (NIH, Bethesda, MD) and adjusted for semi-quantification to

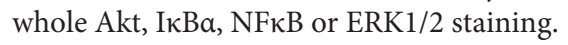

\section{Transcription factor measurement}

The activation of transcription factors (Stat family: Stat-3, Stat-5A, Stat-5B and MAPK family: ATF-2, c-Jun, c-Myc, MEF-2) was analyzed after treatment with adiponectin using TransAM assay kits (Active Motif Europe, Rixensart, Belgium). After 30 minutes 6 incubation with the adipocytokine, $1 \times 105$ SW480 cells per sample were lysed in 20 $\mu \mathrm{l}$ lysis buffer according to the manufacturer's protocol (equivalent to $10 \mu \mathrm{g} / \mathrm{ml}$ protein as was measured by a standard Bradford assay), and subsequently lysates were subjected to TransAM assays. Control experiments were conducted for adiponectin treatment for 15, 30, 60 and $120 \mathrm{~min}$. Because Stat-3 activation had reached its maximum level in SW480 cells at $30 \mathrm{~min}$, this time was chosen for transcription factor measurements throughout. The TransAM assays are based on the binding of the activated transcription factors to an immobilized oligonucleotide consensus sequence. Bound transcription factors were detected by specific primary antibodies and a secondary horseradish peroxidase-conjugated antibody. The assays were performed as described previously [9].

\section{Super array - Real Time PCR}

To detect a human signal transduction pathway-focused gene expression profile of SW480 cells in response to adiponectin we used a RT2 Profiler PCR Array system (SA Biosciences, Frederick, MD, USA) according to the manufacturer's protocol. Using real-time PCR this specific array profiles simultaneously the expression of 84 key genes representative of 18 different signal transduction pathways. After $6 \mathrm{~h}$ cultivation with or without adiponectin, total RNA was directly isolated from SW480 cells using the NucleoSpin RNA II Kit (Macherey-Nagel, Düren, Germany). After cDNA synthesis, the templates were used for PCR in a 96 well plate which already contains gene-specific primer sets. After PCR performance, the relative expression was calculated using the manufacturer's software.

\section{Flow cytometry}

The expression of the interleukin- 8 receptors CXCR1 and CXCR2 was determined using a FacsCalibur flow cytometer (Becton Dickinson, Heidelberg, Germany). Cells were grown for five days in culture medium. Subsequently, 2,5 x 105 cells were fixed with $1 \%$ formaldehyde, 7 and then incubated for $10 \mathrm{~min}$ at room temperature (RT) with the primary monoclonal antibody anti-human CXCR1 and anti-human CXCR2 (R\&D Systems, Wiesbaden, Germany). After washing, we incubated the cells with $10 \mu \mathrm{g} / \mathrm{ml}$ of fluorescein isothiocyanate (FITC)-conjugated anti-mouse antibody (Dianova, 
Hamburg, Germany). Non-specific binding was determined by isotypic control mouse antibody (Coulter-Immunotech, Hamburg, Germany).

The release of a panel of markers known to be involved in the mechanisms and consequences of obesity was measured using a FlowCytomix Human Obesity multiplex kit (Bender MedSystems, Vienna, Austria). After 48 hours of incubation with or without adiponectin in culture medium lacking FCS, in combination with LY294002 $(5 \mu \mathrm{M})$ or NFkB activation inhibitor (10 nM), supernatants of SW480 cells were harvested. The amounts of osteoprotegrin (OPG), interleukin (IL)-8 as well as MCP-1 were measured according to the manufacturer's protocol. The used kit would also have allowed measuring tumor necrosis factor receptor (60kDA; TNF-R)s, CD40L, myeloperoxidase (MPO), IL-6, adiponectin, resistin and leptin which however was in all cases beyond the linear measuring range.

\section{Statistics}

Significant changes were calculated using the Student's $t$ test (two-tailed, unpaired). A probability value of $\mathrm{p}<0.05$ was accepted as statistically significant throughout the experiments.

\section{Results}

\section{Induction of tumor cell migration by adiponectin}

Using our three-dimensional cell migration assay, we could demonstrate that the adipocytokine adiponectin strongly stimulates the migratory activity of human SW480 colon carcinoma cells. After incorporation into a collagen matrix, $30.3 \pm 7.4$ percent of the SW480 cells were spontaneously migratory active (Figure 1A). Stimulation with $10 \mu \mathrm{g} / \mathrm{ml}$ adiponectin resulted in a significant increase of the locomotory activity from an average of $30.3 \pm 7.4$ percent spontaneously migrating cells to $50.9 \pm 8.2(\mathrm{p}=0.003$; Figure $1 \mathrm{~A})$. Next we examined whether the cells express adiponectin receptors to be able to respond to adiponectin. By immunoblotting analysis we could demonstrate that SW480 cells express both adiponectin receptors AdipoR1 and AdipoR2 on their cell surface (Figure 1B).

\section{Regulation of transcription factors by adiponectin}

Adiponectin has been demonstrated to activate members of the MAPK family [13], and to regulate extracellular signal-regulated kinase (ERK) activity [14]. More recently, c-Jun NH2-terminal kinase (JNK) and signal transducer and activator of transcription 3 (Stat-3) were also shown to be downstream effectors of adiponectin [15].

Incubation of SW480 cells with adiponectin led to an activation of Stat family members such as Stat-3, Stat-5a and Stat-5b, whereas the transcription factor Stat- 3 and Stat-5a were significantly activated ( $\mathrm{p}=0.0002$ for Stat -3 and $\mathrm{p}=0.017$ for Stat-5a; Figure $2 \mathrm{~A}$ ). With regard to the activation state of members of the MAPK-family, adiponectintreatment of the cells resulted in a significant increase of p-ATF-2 $(p=0.002)$, and an activation of $c-J u n$ by its phosphorylation, whereas this change in regulation did not reach statistical significance (Figure 2A). In addition, the expression of ERK1/2 or its phosphorylation was not altered upon stimulation with adiponectin as was assessed by immunoblotting (Figure 2B). But we could show an activation of $\mathrm{NF \kappa B}$ after treatment of the cells with adiponectin by demonstrating

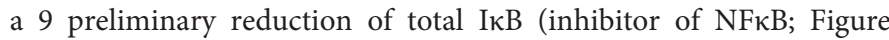

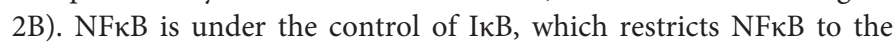
cytoplasm and inhibits its DNA binding activity [16]. Consequently, upon adiponectin treatment of SW480 cells, IкB is phosphorylated

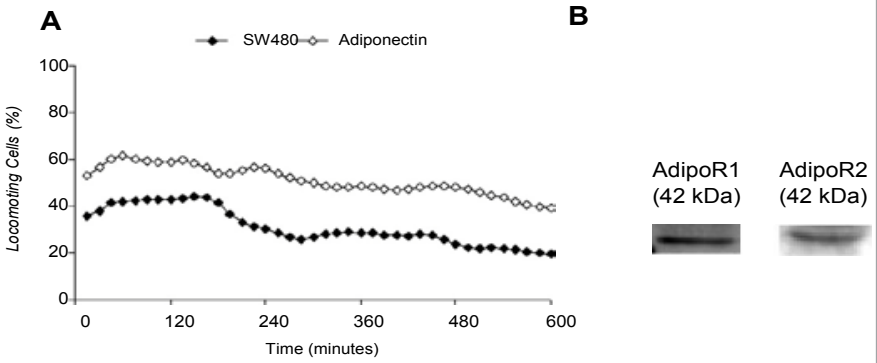

Figure 1: Expression of the adiponectin receptors AdipoR1 and AdipoR2 and their role in the migration of SW480 colon carcinoma cells. In A, the migration of SW480 cells was strongly induced by adiponectin $(p=0.0002)$. The graph shows mean values of three independent experiments (90 cells were analyzed per sample). B, immunoblotting analysis of the expression of AdipoR1 and AdipoR2..

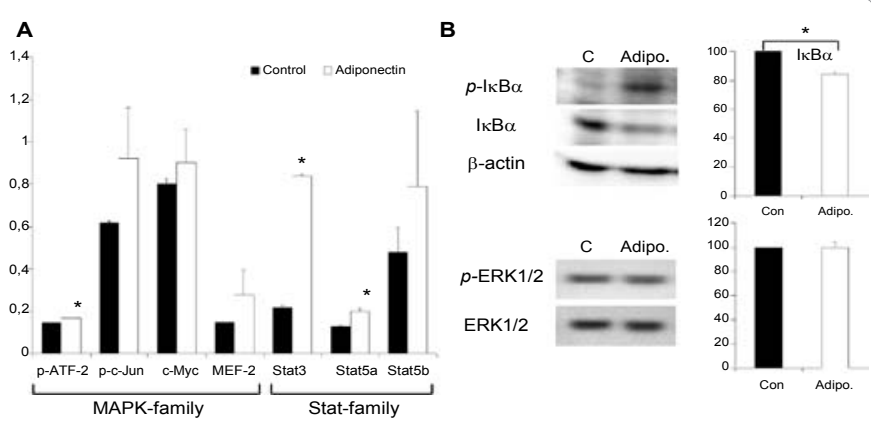

Figure 2: Regulation of transcription factors. In $A$, the graphs show mean intensities and standard deviation of the measured optical density $(450 \mathrm{~nm})$ of control cells (black) and adiponectin-treated cells (white) of three independently performed experiments. We used the Student's t-test to calculate statistical significance; changes with a p-value $\leq 0.02$ are marked by an asterisk. B, immunoblots of total and phosphorylated $1 \mathrm{KBa}$ and Erk1/2 in SW480 cells after incubation with adiponectin for 15 minutes. $\beta$-Actin was used as standard to adjust the applied protein amounts. The graphs show mean values and standard deviation of four independent experiments. Changes with a $p$-value $=$ 0.0001 are marked by an asterisk.

at serine and subsequently degraded (Figure $2 \mathrm{~B}$; upper part), thereby releasing $\mathrm{NFKB}$ and allowing its transition to the nucleus. This increase of $\mathrm{p}-\mathrm{I} \kappa \mathrm{B}$ is followed by a decrease of total I $\mathrm{kB}$. Accordingly, stimulation with adiponectin significantly decreased the total amount of I $\mathrm{B}$ by 16\% (Figure 2B; middle part; $\mathrm{p}=0.0001$ ).

\section{The intracellular signal transduction of adiponectin-induced cell migration}

Since treatment of SW480 cells with adiponectin resulted in an activation of various transcription factors such as Stat-3 or NFkB, we analyzed whether these pathways are functionally involved in the adiponectin-induced migration. For inhibition of the Stat-3 pathway we utilized a Stat-3 specific inhibitory peptide, leading to the reduction of active Stat3: Stat3 dimers levels that can bind DNA, in our cell migration assay. Treatment of the cells with this specific peptide did not affect the spontaneous migration of SW480 cells, but completely abrogated the adiponectin-mediated increase of locomotion from $51.3 \pm 3.5$ percent migrating cells to $23.1 \pm 2.8(\mathrm{p}=0.0002$; Figure $3 \mathrm{~A})$. In parallel, incubation of the cells with the $10 \mathrm{nM} \mathrm{NF \kappa B}$ activation inhibitor specifically inhibited the adiponectin-induced migration, but not the spontaneous locomotion of the cells ( $\mathrm{p}=0.009$; Figure $3 \mathrm{~B})$.

Adiponectin effects were shown to be mediated by the PI3 kinase 
Citation: Ratke J, Niggemann B, Lang K, Zänker KS (2013) A Novel Role of Adiponectin: Stimulator of Human SW480 Colon Carcinoma Cell Migration by Inducing an Autocrine IL-8 and MCP-1 Loop. J Cancer Sci Ther 5: 150-157. doi:10.4172/1948-5956.1000202

signalling pathway $[17,18]$, which is known to play an essential role for cell migration [19]. Here, inhibition of the PI3K with $5 \mu$ M LY294002 abolished the significant $(\mathrm{p}=0.03)$ induction caused by adiponectin (Figure 3C): as compared to the control (25.7 \pm 6.4 percent locomoting cells), $45.1 \pm 6.5$ percent of the cells migrated after addition of adiponectin, but $22.8 \pm 5.3$ percent of the cells migrated after treatment with adiponectin and LY294002 in combination $(\mathrm{p}<0.03)$. LY294002 alone had no effect $(23.9 \pm 3.0$ percent locomoting cells). PI3K is known to mediate its effects on cell migration via several signalling molecules such as Akt/protein kinase B [19]. Akt is phosphorylated by the phosphoinositide-dependent kinase-1, which is activated on PIP3 binding [20]. In turn, Akt/protein kinase B has several substrates involved in the regulation of cell migration such as girdin, that plays an important role in actin organization and Akt-dependent cell motility in fibroblasts and a variety of cancer cell lines [21]. Herein, treatment of the cells with adiponectin strongly increased the phosphorylation of Akt, whereas this phosphorylation was prevented by LY294002treatment (Figure 3D). Stimulation with adiponectin led to an increase of the phosphorylation by $26 \%$, whereas LY294002 alone reduced the phosphorylation to $51 \%$. Incubation with both substances led to a reduction to $42 \%$ of the control (Figure 3D). In addition, several studies have demonstrated that $\mathrm{NFKB}$ and Akt signalling pathways can converge; I $\mathrm{B} B$ kinase is a substrate of Akt, and activation of Akt therefore stimulates NFKB activity [22]. To examine whether the stimulation of $\mathrm{NF \kappa B}$ is in fact a consequence of Akt activation, we incubated the cells with LY294002. Treatment with this specific PI3K inhibitor reduced NFkB phosphorylation induced by adiponectin (Figure 3D), thus demonstrating the involvement of Akt in the stimulation of NFkB activity.

\section{Adiponectin induces the expression of various genes and the release of certain cytokines}

In continuation of the findings that adiponectin significantly activates various transcription factors, including Stat-3, Stat-5a and $\mathrm{NF \kappa B}$, we investigated changes in gene expression after treatment of the cells with adiponectin using a specific real-time PCR array which profiles simultaneously the expression of 84 key genes representative of 18 different signal transduction pathways. Upon adiponectin treatment, we found a significant upregulation of various genes such as chemokine ligand (CCL) 20, CCL 2 (also known as MCP-1) and IL-8 (Figure $4 \mathrm{~A}$ ), whereas only a few genes were detectable demonstrating a downregulation to a small but significant extent (Figure 4A).

Consequently, we next investigated the impact of adiponectin on the release of a panel of markers known to be involved in the mechanisms and consequences of obesity in comparison to untreated control cells. Recent studies have shown that adiponectin can induce the production and secretion of various chemokines such as IL- 8 and MCP-1 in colonic epithelial cells [23] as well as endothelial cells and monocytes [24]. Adiponectin-stimulated SW 480 cells release detectable amounts of various marker molecules that we have investigated (Figure 4B). The highest concentrations in untreated SW480 cells were measured for osteoprotegerin (OPG; $646.7 \pm 38.9 \mathrm{pg} / \mathrm{ml})$. IL-8 (22.6 $\pm 11.0 \mathrm{pg} / \mathrm{ml}), \mathrm{MCP}-1(24.7 \pm 24.3 \mathrm{pg} / \mathrm{ml})$ and tumor necrosis factor receptor (sTNF-R; $0.13 \pm 0.11 \mathrm{ng} / \mathrm{ml}$ ) were only marginally secreted by

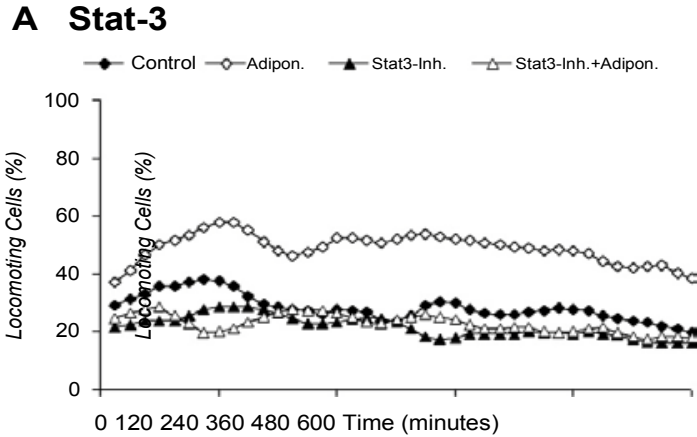

C PI3K

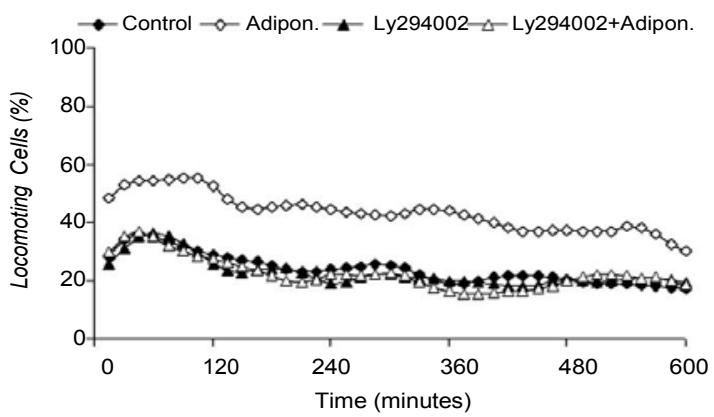

B NFKB

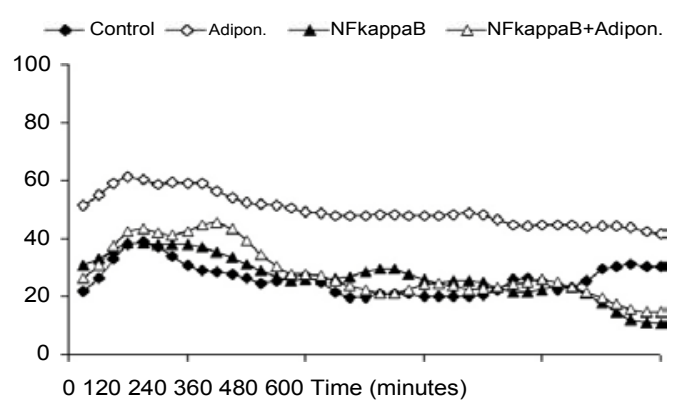

D

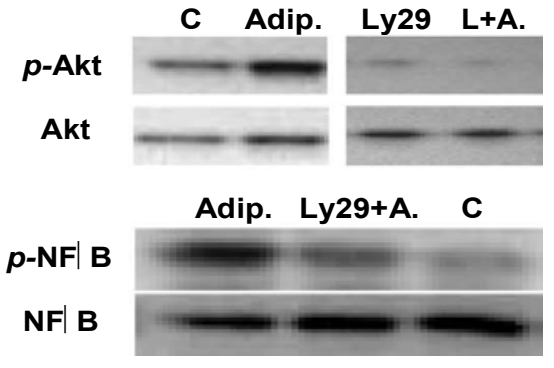

Figure 3: Involvement of Stat-3, NFKB and PI3K in the adiponectin-stimulated migration of SW480 cells. A, the activity of Stat-3 was blocked using $200 \mu \mathrm{g} / \mathrm{ml}$ of specific Stat-3 inhibitor peptide. B, NFKB activation was suppressed by incubation of the cells with $10 \mathrm{nM}$ of NFKB activation inhibitor, and in C, PI3K was inhibited by treatment of the cells with $5 \mu \mathrm{M}$ of the specific inhibitor LY294002. The graphs show mean values of 3 independent experiments (90 cells were analyzed per sample). None of the inhibitor concentrations reduced the viability of the cells as was assessed by propidium-iodide staining and flow cytometry. Statistical significance ( $\mathrm{p}<0.05)$ was calculated using Student's t-test. D, immunoblots of total and phosphorylated NFKB and Akt after incubation of SW480 cells for 35 minutes (NFkB) or 15 minutes (Akt) with adiponectin and Ly294002 alone or in combination. 
Citation: Ratke J, Niggemann B, Lang K, Zänker KS (2013) A Novel Role of Adiponectin: Stimulator of Human SW480 Colon Carcinoma Cell Migration by Inducing an Autocrine IL-8 and MCP-1 Loop. J Cancer Sci Ther 5: 150-157. doi:10.4172/1948-5956.1000202

control cells, and soluble CD40L, adiponectin, resistin and leptin were not detectable at all. However, upon treatment with adiponectin the release of IL-8, OPG and MCP-1 were significantly increased: for IL-8 from $22.6 \pm 11.0 \mathrm{pg} / \mathrm{ml}$ to $523.2 \pm 190.3 \mathrm{pg} / \mathrm{ml}(\mathrm{p}=0.01)$, for MCP-1 from $24.7 \pm 24.3 \mathrm{pg} / \mathrm{ml}$ to $442.1 \pm 218.1 \mathrm{pg} / \mathrm{ml}$ ( $\mathrm{p}=0.03)$, for OPG from $646.7 \pm 38.9 \mathrm{pg} / \mathrm{ml}$ to $804.9 \pm 77.9 \mathrm{pg} / \mathrm{ml}(\mathrm{p} \leq 0.035)$. The concentration of sTNF-R remained unchanged after incubation of SW480 cells with adiponectin (Figure 4B). Interestingly, the adiponectin-mediated release of these substances could be inhibited by addition of the PI3Kinhibitor LY294002 and/or the NFKB activation inhibitor (Figure 4B). Incubation with adiponectin in combination with the $\mathrm{NF \kappa B}$ activation inhibitor significantly reduced the release of OPG and IL-8 even under control level ( $\mathrm{p} \leq 0.035)$. Treatment of SW480 cells with adiponectin and LY294002 decreased solely the secretion of MCP-1 to a significant extent $(\mathrm{p}=0.035)$.

\section{Interleukin- 8 and $\mathrm{MCP}-1$ release in response to adiponectin and its consequences}

Several studies have reported that constitutive expression of IL-8 and its receptors in colon carcinoma cells correlates with different metastatic potentials [25] and malignancy [26]. We have shown previously that IL-8 can stimulate the migration of carcinoma cells in an autocrine manner 11. In continuation of our results herein, demonstrating an increased gene expression and secretion of IL-8 in response to adiponectin, we have investigated the expression of the IL-8 receptors CXCR1 and CXCR2 on the surface of SW480 cells by flow cytometry. Both receptors are expressed on SW480 cells (Figure5A). Antibody-staining of CXCR1 led to an antibody-bound MFI of 72.1, CXCR2 to an MFI of 31.1, whereas staining with an unspecific isotypic antibody resulted in an MFI of 5.6. Treatment of the cells with either adiponectin or IL-8 did not change the expression level of these two IL-8 receptors (data not shown). Using an IL-8 neutralizing antibody, we could show a significant reduction of the adiponectin-induced locomotory activity of the colon carcinoma cells from $43.14 \pm 4.46 \%$ to $25.9 \pm 3.38 \%$ locomoting cells at $10 \mu \mathrm{g} / \mathrm{ml}$ of the neutralizing IL- 8 antibody ( $\mathrm{p}=0.006$; Figure $5 \mathrm{~B})$. Moreover, incubation of the cells with a MCP-1 neutralizing antibody $(10 \mu \mathrm{g} / \mathrm{ml})$ specifically abolished the adiponectin-mediated migration of the cells, too (Figure 5C). This indicates that adiponectin mediates its strong pro-migratory effect on SW480 human colon carcinoma cells via the engagement of an

A Homebox A1
Protein kinase C, epsilon
Bascular endothelial growth factor
Baculoviral IAP repeat-containing
Interferon regulatory factor 1 Nuclear factor of kappa light polypeptide gene enhancer in B-cells Bone morphogenetic protein 2 Matrix metallopeptidase 7 (matrilysin, uterine) Intercellular adhesion molecule 1 (CD54), human rhinovirus recepto TRAF family member-associated NFKB activatoColony stimulating factor 2 (granulocyte-macrophage) Lymphotoxin alpha (TNF superfamily, member Baculoviral IAP repeat-containing Tumor necrosis factor (TNF superfamily, member 2 Chemokine (C-C motif) ligand Chemokine (C-C motif) ligand 20

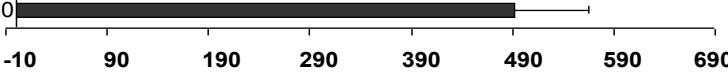

B

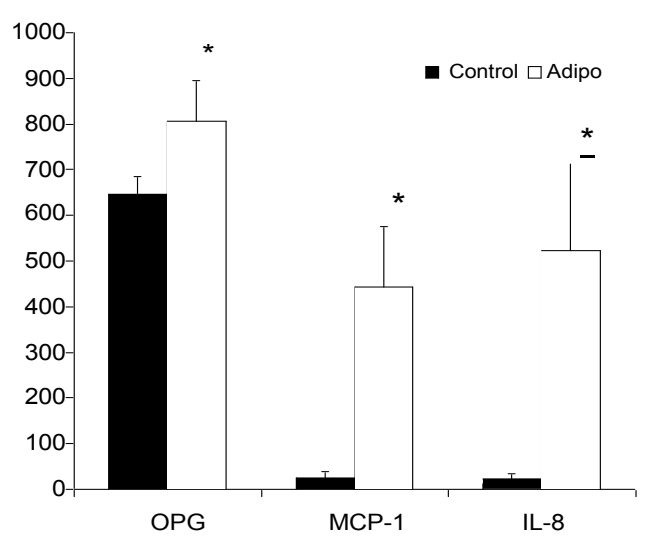

Figure 4: Changes in gene expression and cytokine release of SW480 cells in response to adiponectin. A, SuperArray results; SW480 cells significantly regulate the expression of certain genes representative of 18 different signal transduction pathways after incubation with adiponectin for 6 hours. Mean values and standard deviation of the up- and downregulation of genes in response to adiponectin are given in relation to untreated control cells of three independent experiments. Solely the statistically significant gene expression changes are shown. B, cytokine release of SW480 cells after two days incubation with or without adiponectin in combination with LY294002 or NFKB activation inhibitor in culture medium lacking FCS. The graphs show mean intensities and standard deviation of three independently carried out experiments. We used Student's t-test to calculate statistical significance. Changes with $p \leq 0.035$ are marked by an asterisk. 
A

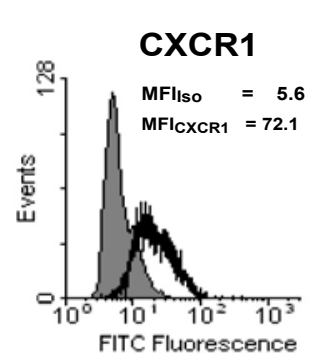

C

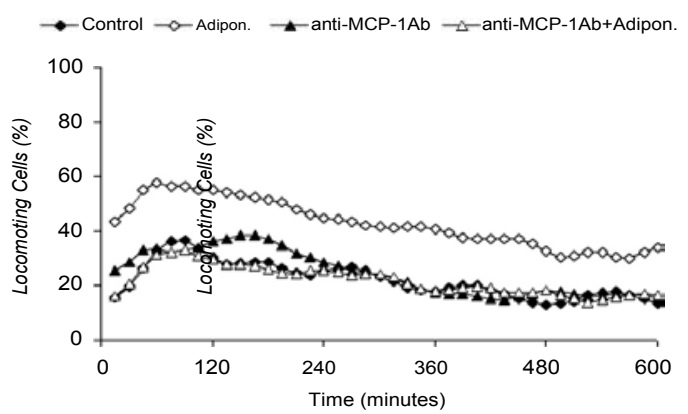

B

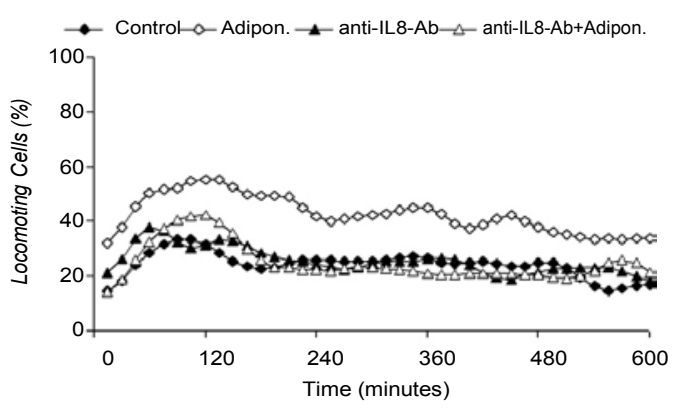

D

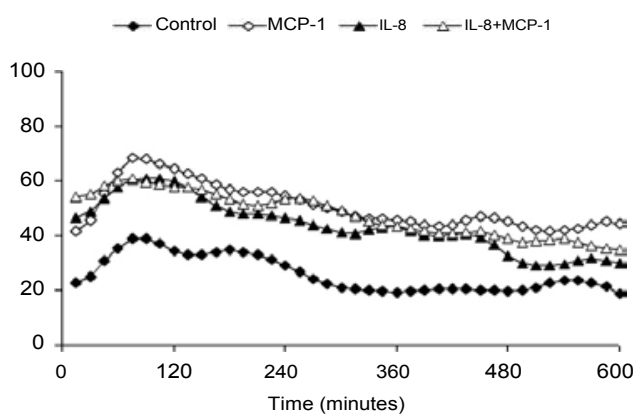

Figure 5: Adiponectin-induced SW480 cell migration via an autocrine IL-8 and MCP-1 release. A, expression of the interleukin-8 receptors CXCR1 and CXCR2 on the surface of SW480 cells was determined using flow cytometry. The antibody-bound FITC-fluorescence of specific antibodies (black line) was compared to an unspecific isotype control (gray area). MFI = mean fluorescence intensity of specific (CXCR1 and CXCR2) and isotypic (Iso) binding. The shown histogram holds true for 3 measurements that have been performed independently. B, the adiponectin-induced migratory activity of SW480 cells was inhibited by additional treatment of the cells with $10 \mu \mathrm{g} / \mathrm{ml}$ of an IL-8-neutralizing antibody. C, incubation of SW480 cells with $10 \mu \mathrm{g} / \mathrm{ml}$ MCP-1-neutralizing antibodies abolished the adiponectin-mediated cell locomotion. D, stimulation of SW480 cell migration with $100 \mathrm{ng} / \mathrm{ml} \mathrm{IL-8}$ and $20 \mathrm{ng} / \mathrm{ml} \mathrm{MCP-1}$ alone or in combination. The graphs show mean values of 3 independent experiments ( 90 cells were analyzed per sample).

autocrine IL-8 and MCP-1 loop. To further prove the existence of the autocrine mechanism, we stimulated SW480 cells with IL-8 and MCP-1 alone and in combination. Convincingly, both ligands alone significantly increased the locomotion of SW480 cells to the same extent as adiponectin (Figure 5D). However, there is no additive effect on migration when using the combination of both ligands. In short, adiponectin seems to enhance the migration of SW480 colon carcinoma cells by inducing the production and release of at least IL-8 as well as MCP-1, which can then bind to their appropriate receptors, resulting in the significant initiation of cell migration.

\section{Discussion}

Recent studies have revealed that fat tissue is an important endocrine organ producing various adipocytokines. The most prominent are leptin and adiponectin, both of which are strongly correlated with obesity [27]. We have shown previously, that leptin has a significant impact on the migratory activity of human colon carcinoma cells8. With regard to adiponectin only a handful of studies exist, which have demonstrated that its expression enhances tumorigenesis and metastastis of e.g. breast [28] or prostate cancer cells [29]. Herein, we show for the first time that adiponectin is a strong stimulator for the migration of SW480 colon carcinoma cells, which is intracellularly mediated by multiple signaling pathways which we will discuss in the following. At first, we have verified that these cells express both adiponectin receptors (AdipoR1 and AdipoR2). Moreover, treatment of the cells with adiponectin resulted in a significant increase of the locomotor activity from $30 \%$ spontaneously migrating cells to $51 \%$ (Figure $1 \mathrm{~A}$ ). Adiponectin, via its specific receptors, is known to mediate several intracellular signaling pathways such as Jak/Stat [15], MAP kinase [13] and via ERK activity [14]. These results on the involvement of adiponectin in the regulation of transcription are partially in concurrence with our findings on SW480 cells. We observed a significant activation of Stat-3, Stat$5 \mathrm{a}$ and p-ATF-2 after incubation of SW480 cells with adiponectin, whereas we could not detect a phosphorylation of ERK1/2 (Figure 2). Instead, adiponectin-treatment resulted in an activation of NFKB, too, which has already been shown in prostate cancer cells [29] and primary human hepatocytes [30] before. In monocytic cell-lines, this adiponectin-mediated activation of NFKB was attenuated amongst others by an inhibitor of PI3K [31]. The PI3K is known to be a key molecule regulating cell migration [19]. Herein, treatment of SW480 cells with adiponectin resulted in an activation of PI3K, because the adiponectin mediated increase of SW480 cell migration was abrogated by using LY294002, a specific inhibitor of the PI3K. This is consistent with previous findings demonstrating that the leptin-induced migration of SW480 cells was impaired by the inhibition of PI3K [8]. The $14 \mathrm{PI} 3 \mathrm{~K} /$ Akt pathways is frequently altered in human cancers [20], and an activation of the phosphoinositide-dependent kinase-1 and Akt is correlated with invasive and metastasizing breast tumors [32]. Accordingly, Akt is already phosphorylated in the tumor cells used herein without a stimulus, and further enhanced after incubation with adiponectin, whereas LY294002 effectively inhibited this phosphorylation. It is thus likely that Akt is a downstream mediator of the PI3K for the stimulation of migratory activity. Moreover, we could demonstrate that the activation of the PI3K/Akt pathway also stimulates NFKB activity. Because treatment of the cells with the PI3K 
inhibitor decreased not only the phosphorylation of Akt but from $\mathrm{NF \kappa B}$, too, as was shown by immunoblotting (Figure 3D).

In parallel, we herein show that the activation of NFKB and Stat-3 are necessary events for the adiponectin-induced migration, because usage of a Stat-3 specific inhibitory peptide and NFkB activation inhibitor completely abrogated the adiponectin-driven locomotion of SW480 cells, respectively, without affecting the spontaneous, matrixinduced locomotion (Figures $3 \mathrm{~A}$ and $3 \mathrm{~B}$ ). All these transcription factors activated by adiponectin are known to modulate the expression of a plethora of genes necessary for cell migration and signal transduction pathways in general. Utilizing the RT-PCR technique, we have found a significant upregulation of various genes such as IL-8, MCP-1 and CCL20 upon incubation with adiponectin (Figure 4A), and a few genes were detectable demonstrating a downregulated expression to a small but significant extent. These three most highly up-regulated genes in this study, CCL20, MCP-1 and IL-8, are all chemokines. Whereas CCL20 and MCP-1 are known to attract immune cells, IL- 8 has been shown to induce the migration of immune cells as well as tumor cells [11]. Previous studies have shown that adiponectin can induce the production and secretion of various chemokines such as IL-8 and MCP-1 in colonic epithelial cells [23] as well as endothelial cells and monocytes [24]. Thus, adiponectin may promote the release of these chemokines by SW480 cells to initiate their migration in an autocrine fashion. Consequently, we have evaluated the release of various chemokines and markers especially known to be [15] involved in the mechanisms and consequences of obesity. Interestingly, we found that incubation of SW480 cells with adiponectin significantly increases the release of MCP-1 and IL-8 (Figure 4B). Moreover, using an interleukin-8 or MCP-1 neutralizing antibody, we were able to abolish the adiponectin-induced locomotor activity of SW480 cells, respectively (Figures 5B and 5C). As shown by flow cytometry SW480 colon carcinoma cells express e.g. both IL-8 receptors CXCR1 and CXCR2; therefore, the released IL-8 can bind in an autocrine loop and thus stimulate cell migration. To further prove the existence of the autocrine mechanism, we stimulated SW480 cells with IL- 8 and MCP-1 alone and in combination. Convincingly, both ligands alone significantly increased the locomotion of SW 480 cells to the same extent as adiponectin (Figure 5D). However, there is no additive effect on migration when using the combination of both ligands. Furthermore, this autocrine mechanism is intracellularly regulated via the activation

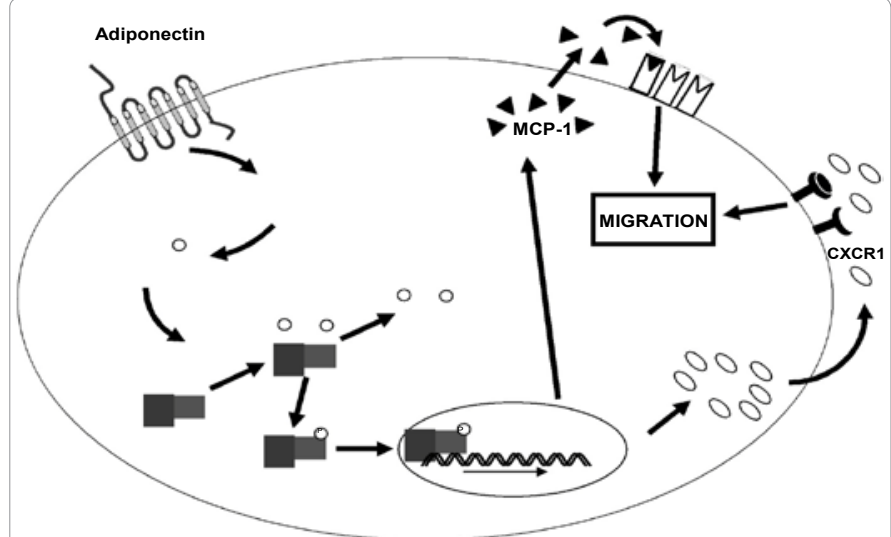

Figure 6: Model of the intracellular signal transduction pathway regulating the adiponectin-induced locomotion of SW480 colon carcinoma cells. PI3K: phosphatidyl-inositol-3-kinase, NFKB: nuclear factor $K B$, IKBa: inhibitor of NFKB, IL-8: interleukin-8, MCP-1: monocyte chemoattractant protein-1.

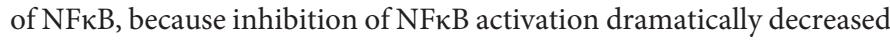
the release of IL- 8 and MCP-1, and consequently the adiponectinstimulated migration, too. In short, adiponectin seems to enhance the migration of SW 480 colon carcinoma cells by inducing the production and release of at least IL- 8 as well as MCP-1, which can then bind to their appropriate receptors, resulting in the significant initiation of cell migration (Figure 6).

In summary, our data for the first time demonstrate a pro-migratory effect of the adiponectin on SW480 colon carcinoma cells, and deciphere the molecular mechanisms responsible for the adipocytokine-mediated migration establishing direct association between obesity and colonic carcinogenesis, and presenting involvement of key molecules of multiple signaling pathways. In conclusion, our results, together with the previously reported pro-migratory action of leptin strengthen the role of adipose cells as a producer of signals modulating the migration of colon carcinoma cells.

\section{Acknowledgements}

We thank Gaby Troost for excellent technical assistance. This work was supported by the Fritz Bender Foundation, Munich, Germany.

\section{References}

1. Kelesidis I, Kelesidis T, Mantzoros CS (2006) Adiponectin and cancer: a systematic review. Br J Cancer 94: 1221-1225.

2. Chandran M, Phillips SA, Ciaraldi T, Henry RR (2003) Adiponectin: more than just another fat cell hormone? Diabetes Care 26: 2442-2450.

3. Wei EK, Giovannucci E, Fuchs CS, Willett WC, Mantzoros CS (2005) Low plasma adiponectin levels and risk of colorectal cancer in men: a prospective study. J Natl Cancer Inst 97: 1688-1694.

4. Michalakis K, Williams CJ, Mitsiades N, Blakeman J, Balafouta-Tselenis S, et al. (2007) Serum adiponectin concentrations and tissue expression of adiponectin receptors are reduced in patients with prostate cancer: a case control study. Cancer Epidemiol Biomarkers Prev 16: 308-313.

5. Dal Maso L, Augustin LS, Karalis A, Talamini R, Franceschi S, et al. (2004) Circulating adiponectin and endometrial cancer risk. J Clin Endocrinol Metab 89: 1160-1163

6. Karaduman M, Bilici A, Ozet A, Sengul A, Musabak U, et al. (2007) Tissue levels of adiponectin in breast cancer patients. Med Oncol 24: 361-366.

7. Petridou ET, Mitsiades N, Gialamas S, Angelopoulos M, Skalkidou A, et al (2007) Circulating adiponectin levels and expression of adiponectin receptors in relation to lung cancer: two case-control studies. Oncology 73: 261-269.

8. Ratke J, Entschladen F, Niggemann B, Zänker KS, Lang K (2010) Leptin stimulates the migration of colon carcinoma cells by multiple signaling pathways. Endocr Relat Cancer 17: 179-189.

9. Lang K, Drell TL 4th, Lindecke A, Niggemann B, Kaltschmidt C, et al. (2004) Induction of a metastatogenic tumor cell type by neurotransmitters and its pharmacological inhibition by established drugs. Int J Cancer 112: 231-238.

10. Entschladen F, Drell TL 4th, Lang K, Joseph J, Zaenker KS (2004) Tumour-cel migration, invasion, and metastasis: navigation by neurotransmitters. Lance Oncol 5: 254-258.

11. Lang K, Niggemann B, Zanker KS, Entschladen F (2002) Signal processing in migrating T24 human bladder carcinoma cells: role of the autocrine interleukin- 8 loop. Int J Cancer 99: 673-680.

12. Laemmli UK (1970) Cleavage of structural proteins during the assembly of the head of bacteriophage T4. Nature 227: 680-685.

13. Mao X, Kikani CK, Riojas RA, Langlais P, Wang L, et al. (2006) APPL1 binds to adiponectin receptors and mediates adiponectin signalling and function. Nat Cell Biol 8: 516-523.

14. Mao X, Hong JY, Dong LQ (2006) The adiponectin signaling pathway as a novel pharmacological target. Mini Rev Med Chem 6: 1331-1340.

15. Miyazaki T, Bub JD, Uzuki M, Iwamoto Y (2005) Adiponectin activates c-Jun 
Citation: Ratke J, Niggemann B, Lang K, Zänker KS (2013) A Novel Role of Adiponectin: Stimulator of Human SW480 Colon Carcinoma Cell Migration by Inducing an Autocrine IL-8 and MCP-1 Loop. J Cancer Sci Ther 5: 150-157. doi:10.4172/1948-5956.1000202

$\mathrm{NH} 2$-terminal kinase and inhibits signal transducer and activator of transcription 3. Biochem Biophys Res Commun 333: 79-87.

16. Tran K, Merika M, Thanos D (1997) Distinct functional properties of IkappaB alpha and IkappaB beta. Mol Cell Biol 17: 5386-5399.

17. Benaitreau D, Dieudonné MN, Dos Santos E, Leneveu MC, Mazancourt Pd, et al. (2009) Antiproliferative effects of adiponectin on human trophoblastic cell lines JEG-3 and BeWo. Biol Reprod 80: 1107-1114.

18. Barb D, Williams CJ, Neuwirth AK, Mantzoros CS (2007) Adiponectin in relation to malignancies: a review of existing basic research and clinical evidence. Am J Clin Nutr 86: s858-s866.

19. Bastian P, Posch B, Lang K, Niggemann B, Zaenker KS, et al. (2006) Phosphatidylinositol 3-kinase in the $G$ protein-coupled receptor-induced chemokinesis and chemotaxis of MDA-MB-468 breast carcinoma cells: a comparison with leukocytes. Mol Cancer Res 4: 411-421.

20. Osaki M, Oshimura M, Ito $H$ (2004) PI3K-Akt pathway: its functions and alterations in human cancer. Apoptosis 9: 667-676.

21. Jiang $P$, Enomoto A, Jijiwa M, Kato T, Hasegawa T, et al. (2008) An actinbinding protein Girdin regulates the motility of breast cancer cells. Cancer Res 68: $1310-1318$

22. Meng F, Liu L, Chin PC, D'Mello SR (2002) Akt is a downstream target of NFkappa B. J Biol Chem 277: 29674-29680.

23. Ogunwobi OO, Beales IL (2006) Adiponectin stimulates proliferation and cytokine secretion in colonic epithelial cells. Regul Pept 134: 105-113.

24. Rovin BH, Song H (2006) Chemokine induction by the adipocyte-derived cytokine adiponectin. Clin Immunol 120: 99-105.

25. Li A, Varney ML, Singh RK (2001) Expression of interleukin 8 and its receptors in human colon carcinoma cells with different metastatic potentials. Clin Cancer Res 7: 3298-3304.

26. Baier PK, Eggstein S, Wolff-Vorbeck G, Baumgartner U, Hopt UT (2005) Chemokines in human colorectal carcinoma. Anticancer Res 25: 3581-3584.

27. Staiger H, Tschritter O, Machann J, Thamer C, Fritsche A, et al. (2003) Relationship of serum adiponectin and leptin concentrations with body fat distribution in humans. Obes Res 11: 368-372.

28. Miyoshi Y, Funahashi T, Kihara S, Taguchi T, Tamaki Y, et al. (2003) Association of serum adiponectin levels with breast cancer risk. Clin Cancer Res 9: 5699-5704.

29. Tang $\mathrm{CH}$, Lu ME (2009) Adiponectin increases motility of human prostate cancer cells via adipoR, p38, AMPK, and NF-kappaB pathways. Prostate 69 1781-1789.

30. Wanninger J, Neumeier M, Weigert J, Bauer S, Weiss TS, et al. (2009) Adiponectin-stimulated CXCL8 release in primary human hepatocytes is regulated by ERK1/ERK2, p38 MAPK, NF-kappaB, and STAT3 signaling pathways. Am J Physiol Gastrointest Liver Physiol 297: G611-G618.

31. Haugen F, Drevon CA (2007) Activation of nuclear factor-kappaB by high molecular weight and globular adiponectin. Endocrinology 148: 5478-5486.

32. Lin HJ, Hsieh FC, Song H, Lin J (2005) Elevated phosphorylation and activation of PDK-1/AKT pathway in human breast cancer. Br J Cancer 93: 1372-1381. 